\title{
SUZANNE DAVEAU E A ARQUEOLOGIA: TEMPO E ESPAÇO
}

\author{
VICTOR S. GONÇALVES ${ }^{1}$
}

\begin{abstract}
Sous les ifs noirs qui les abritent Les hibous se tiennent rangés Ainsi que des dieux étrangers Dardant leur œil rouge. Ils méditent.

Sans remuer ils se tiendront Jusqu'à l'heure mélancolique Où, poussant le soleil oblique Les ténèbres s'établiront.

Leur attitude au sage enseigne Qu'il faut en ce monde qu'il craigne Le tumulte et le mouvement;

L'homme ivre d'une ombre qui passe Porte toujours le châtiment D'avoir voulu changer de place.
\end{abstract}

Charles Baudelaire

\section{PARA COMEÇAR}

Escrever sobre alguém que conhecemos e que, felizmente, está vivo e produtivo é um privilégio relativamente raro num País que considera os obituários uma excelsa forma de expressão e guarda os nomes das suas ruas para mortos que a grande maioria desconhece. A Morte reina assim, ainda por cima transfigurada num detergente ultra perfeito, limpando erros e baixezas, transformando os que já

1 Professor Catedrático da Faculdade de Letras da Universidade de Lisboa. Director do Centro de Arqueologia da Universidade de Lisboa. Faculdade de Letras - 1699 Lisboa Codex. 
partiram em figuras assexuadas e um pouco tontas, libertas do Mal e do Erro. O que explica a pouca popularidade de uma velha canção de Brassens...

Escrever sobre um vivo tem naturalmente vantagens, problemas e riscos. Para já, apesar de tudo, o objecto da escrita está cá, para nos responder (o que é excelente), mas também para contestar e, eventualmente, nos dar um estalo.

Suzanne Daveau está - não é necessário repeti-lo - viva e bem viva e é com satisfação que recordo as nossas breves mas instrutivas conversas de não há muito tempo. E é com o mesmo empenho que julgo importante mostrar para onde, em meu entender, ela dirigiu o seu olhar, como o fez, e qual a sua contribuição no campo da Arqueologia.

A sua popularidade junto dos arqueólogos letrados, uma espécie que alguns defendem estar em vias de extinção, é próxima da de Orlando Ribeiro, numa direcção. E nas minhas memórias pessoais, apenas avizinhada, e noutro campo, pela de Jorge Gaspar, cuja monografia sobre Évora me varreu definitivamente do espírito a ideia do povoado enquanto entidade de estudo única, isolada, fazendo-me caminhar para a teoria das redes interdependentes de povoamento, provavelmente um dos contributos mais interessantes do meu próprio trabalho sobre as sociedades camponesas do $3^{\circ}$ milénio no Alto Algarve Oriental.

Membro de uma geração de arqueólogos sem antepassados imediatos de que nos pudéssemos orgulhar, encontrei, como outros, referências exteriores ao meu próprio espaço nacional (de início, Gordon Childe, Leroi-Gourhan e David Clarke).

Em Portugal, as figuras que mais se aproximavam do que eu gostaria de fazer estavam, porém, em áreas contíguas. De onde ter sido aluno, por opção, de Jorge Dias, Viegas Guerreiro... e Lindley Cintra. E ter frequentado as aulas de Orlando Ribeiro.

Neste espaço, e no horizonte humano peculiar da Faculdade de Letras de Lisboa, Suzanne Daveau surge com a solidez de um sinclinal, desloca-se cientificamente como uma moreia, não deixando fendas no caminho, e a sua contribuição para a Arqueologia advém afinal de uma leitura integrada da paisagem, do reconhecimento implícito da indispensabilidade dos olhares múltiplos e também, por que não dizê-lo, da infinita curiosidade que o espaço e o tempo lhe provocam.

Que buscamos afinal naquilo que não é exactamente nosso?

Afinidades, incompatibilidades, vizinhança. Três excelentes razões para olharmos para o lado. E é exactamente a razão de esse «olhar» de Suzanne Daveau que menos dúvidas me oferece, chamemos-lhe vizinhança ou contiguidade, pensando à partida em Orlando Ribeiro.

Os olhares de arqueólogos e geógrafos cruzam-se muitas vezes no terreno e, por vezes, têm o mesmo objecto. Numa Faculdade de papel, esse gosto pela terra e por quem a transforma é comum e justifica o meu projecto de 1974, altura em que a Arqueologia (integrada na História) e a Geografia só por pouco não migraram para edifício próprio, como partida para uma Faculdade específica, de Geografia e História, como em Espanha por vezes sucede.

Mas se Orlando Ribeiro nunca escondeu o seu gosto pela síntese, caminho que por vezes, quando excessivamente usado, nos arrasta para perspectivas excessiva- 
mente generalistas, Suzanne Daveau surgiu perante mim por uma razão tão prática que algo deve significar. Trabalhava na minha tese de doutoramento quando questões como a transgressão flandriana e as alterações da linha da costa (perfeitamente marginais, como é fácil perceber, no contexto do Alto Algarve Oriental) me fizeram olhar para o lado, para o Departamento de Geografia. E das primeiras conversas com Suzanne acabaria por sair o convite para a publicação na «nossa» revista, a CLIO da $1^{a}$ série, de um texto que se tornaria rapidamente um clássico.

\section{A LEITURA DO RELEVO}

Antes da veloz evolução dos sistemas informáticos, a rotring do desenhador desempenhou (e ainda hoje desempenha) um papel fundamental. E a definição do sítio geográfico do povoamento fazia-se por leitura directa, «analógica», dos mapas.

Nada de mais interessante que o estudo, por fazer, da evolução da expressão gráfica em Arqueologia. Trabalho que até hoje não colheu atenção. E interessante porque o significado do espaço que os arqueólogos divulgavam (mesmo ainda no tempo relativamente recente em que comecei a escrever a minha tese de doutoramento) era muito específico: era um espaço de localização, não um espaço de compreensão.

Quero com isto dizer que a quase totalidade dos mapas publicados em trabalhos de arqueologia visavam sobretudo mostrar onde o sítio estava em função da localidade mais próxima. Para alguns da minha geração, auto-educados na Escola de Antiga Agricultura inglesa, leitores de Jarman e Higgs e, depois, de Vita-Finzi, Chisholm e Sherratt, isto era o último dos crimes, a justificação para a violência com que por vezes escrevíamos ou falávamos sobre o «estado da arte» da Arqueologia portuguesa. E que nos levava a pensar que no terceiro quartel do séc. XX se fazia pior arqueologia em Portugal que no último do XIX.

Neste contexto, Suzanne Daveau trouxe-nos os blocos diagramas, como forma de visionar o espaço de uma forma que só os ortofotomapas superariam, e ainda assim numa outra direcção.

Comecei assim a descrever o relevo onde se anichavam os povoados que estudava no Alto Algarve Oriental e, logo a seguir, no Alentejo, com recurso a essa leitura gráfica que Suzanne Daveau divulgara num pequeno texto policopiado pelo Centro de Estudos Geográficos, os nossos vizinhos do outro lado (e não se trata aqui de uma das metáforas que tanto aprecio por vezes: o CEG fica exactamente em frente, do outro lado do corredor, do Centro de Arqueologia da Universidade de Lisboa, de onde também a facilidade de conversa com Suzanne ao longo dos anos em que ensinou na Faculdade de Letras).

Mais uma vez, o lápis e a rotring de José Peres funcionaram e, logo na versão inicial, a minha tese de doutoramento (1989. Megalitismo e Metalurgia no Alto Algarve Oriental. 2 vols. Lisboa: INIC/UNIARQ) incluía várias representações gráficas: oro-hidrográficas, geológicas, de capacidade de uso dos solos e...blocos diagramas. 


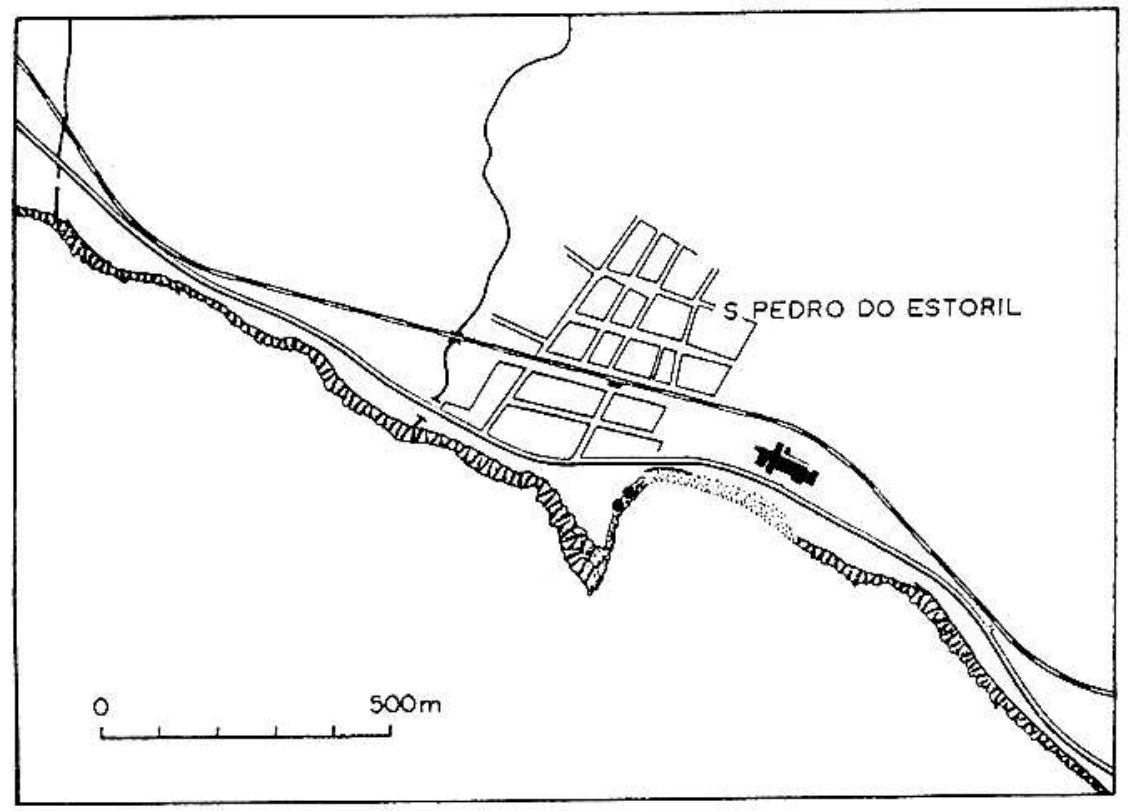

Fig. 1 - Um exemplo, entre dezenas possíveis: a localização das grutas artificiais de S. Pedro do Estoril. A imagem mostra uma vista ultra-esquemática da realidade, sem curvas de nível e com a informação reduzida ao mínimo. Para um trabalho de grande qualidade para a época, uma das raríssimas monografias arqueológicas em que o próprio Caderno de Campo é divulgado, trata-se não de um aspecto menor, mas da verdadeira filosofia da época, que não atribuía normalmente qualquer importância à paisagem envolvente dos monumentos e sítios. (Leisner, Vera; Paço, Afonso do; e Ribeiro, Leonel, 1964, Grutas Artificiais de S. Pedro do Estoril. Lisboa).

Longamente as discuti com Suzanne, que resistia à ideia de se apresentarem para a Pré-História mapas de capacidade de uso dos solos, e esse foi dos poucos pontos em que lhe resisti. Como fundamento, apontei o «conservadorismo» dos solos alto-algarvios e alentejanos, muito pouco transformados pelo Homem, e justamente por sociedades camponesas onde o trigo desempenharia um papel fundamental.

Mas o relevo, a imagem do relevo, a leitura imediata e simples que um bloco diagrama «analógico» ou «digital» fornece, não oferecia dúvidas ou sequer lugar para discussão.

Com Suzanne, tão avessa como eu aos modismos que varrem a nossa pequena comunidade científica, defendi a importância de esta leitura do relevo e a preferência por sistemas de representação de território mais simples (mas por isso mesmo menos sujeitos a variações de erro) que as representações de territórios baseadas em tempos de marcha. E isto apesar de pensar agora que entre duas situações teóricas, uma simples e outra complexa, não é necessariamente a primeira a mais provável de corresponder à realidade ou ao que quer que se lhe assemelhe. 


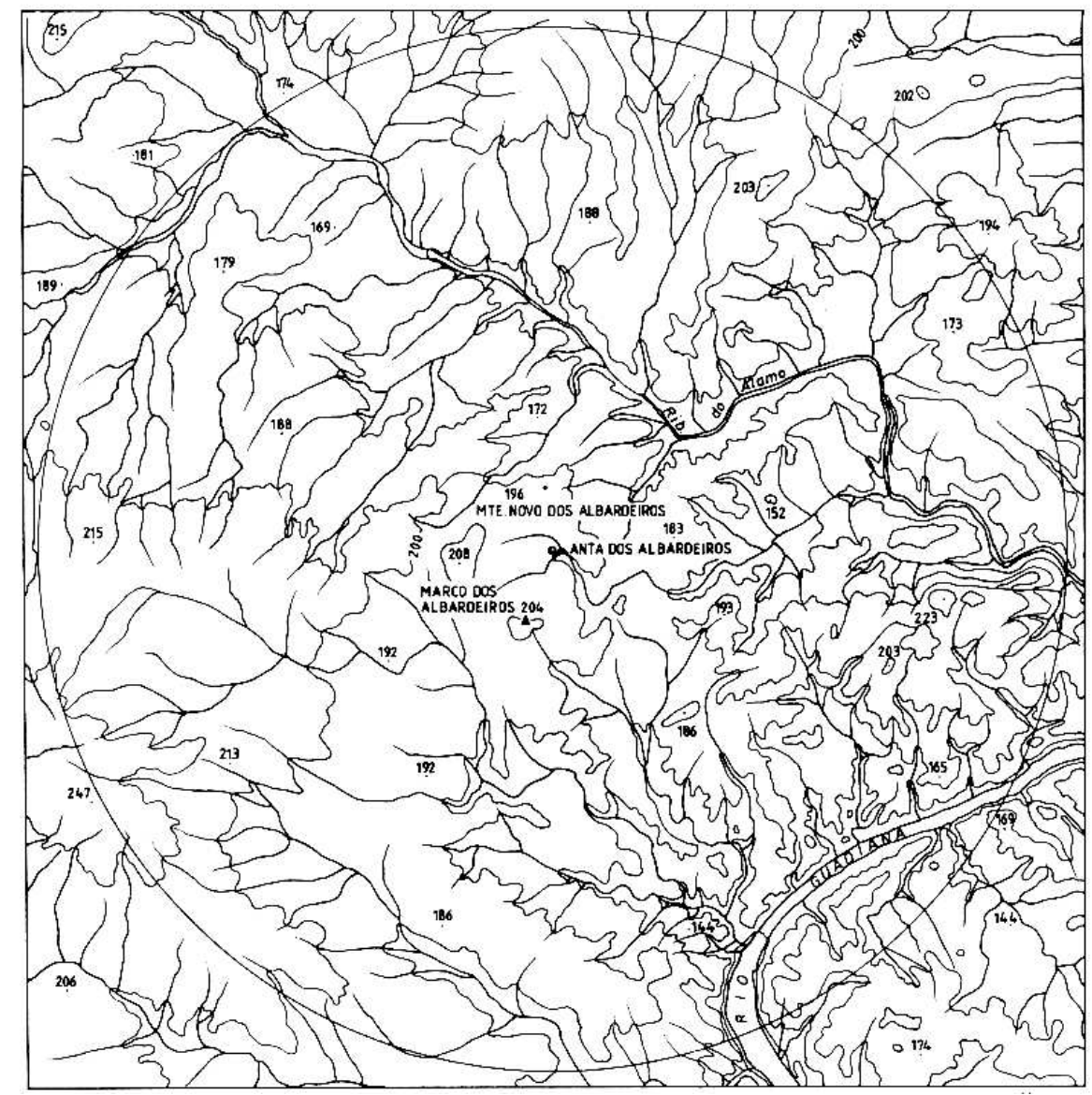

Fig. 2A - O povoado pré-histórico do Monte Novo dos Albardeiros, em Reguengos de Monsaraz. A leitura gráfica ilustra aqui a localização do sítio em função do relevo e das linhas de água, fundamentais para a compreensão da estratégia do povoamento. Indica-se um território provável de aquisição de recursos com um raio de $5 \mathrm{~km}$. (Gonçalves, 1989). 


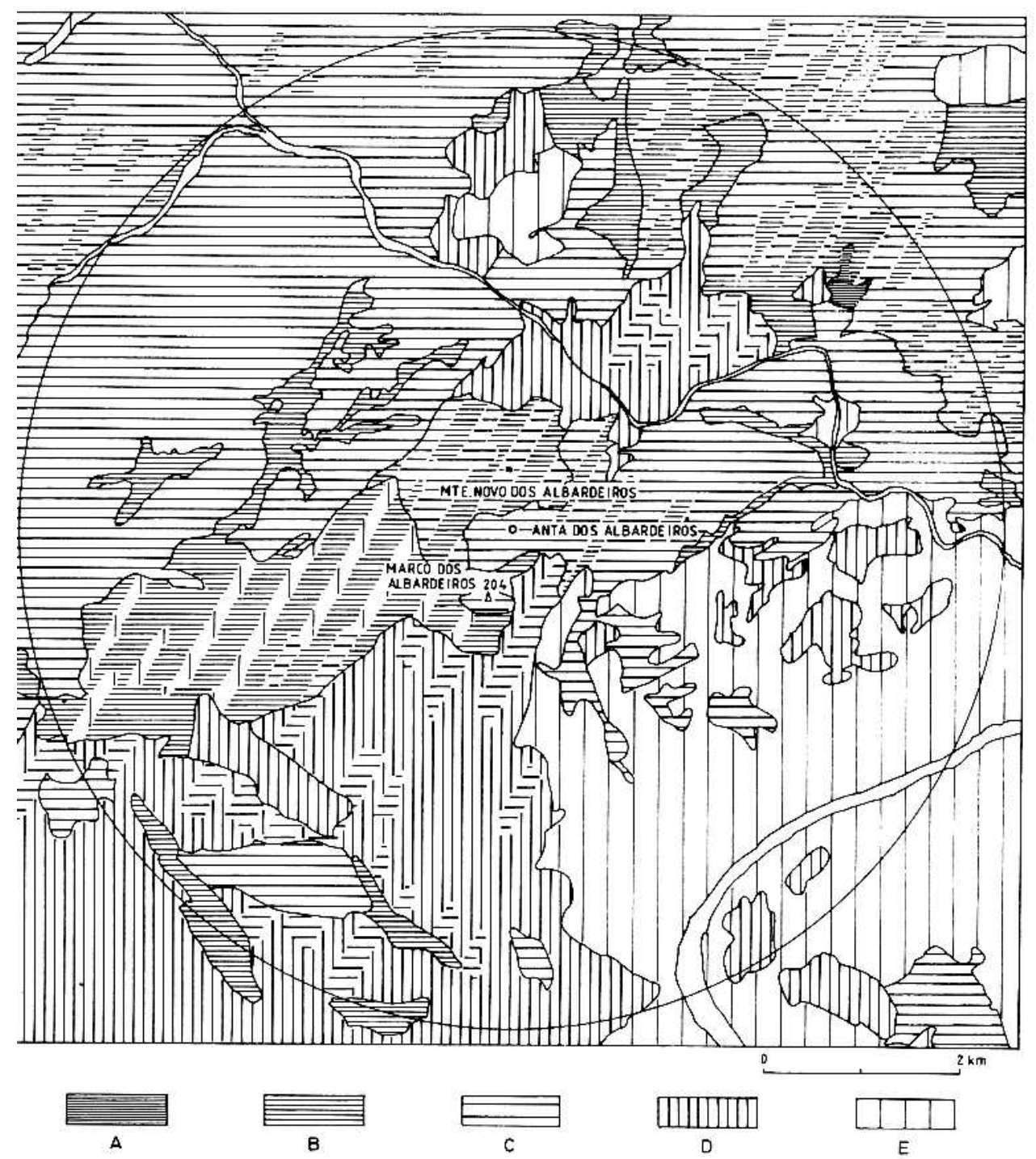

Fig. 2B - O povoado pré-histórico do Monte Novo dos Albardeiros, em Reguengos de Monsaraz. O registo da capacidade de uso dos solos é útil e relativamente fiável em áreas de povoamento escasso, onde os trabalhos agrícolas não alteraram substancialmente as características originais. A importância dos solos de tipo B é aqui superior aos de tipo A, demasiado pesados para serem trabalhados por uma agricultura de enxada ou arado primitivo. 


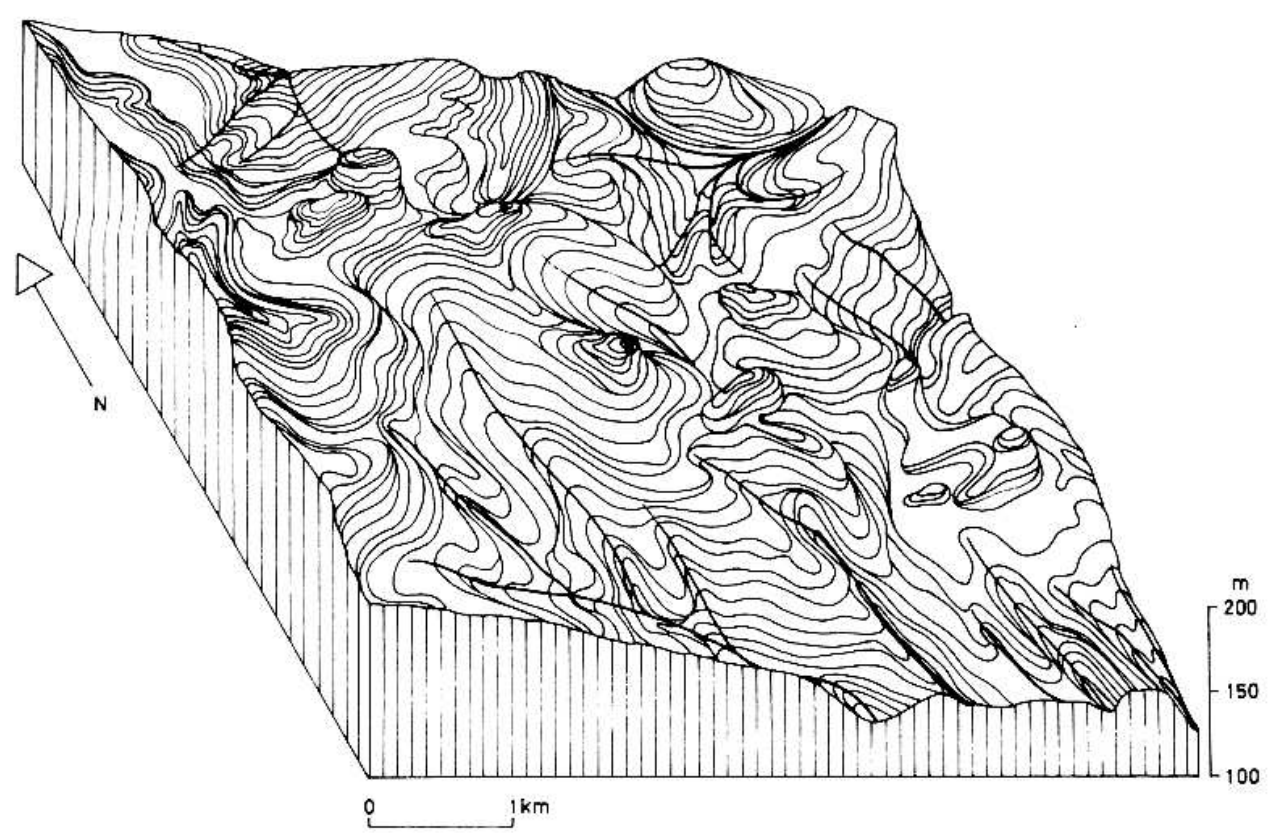

Fig. 2C - Bloco diagrama representando a localização do povoado pré-histórico do Monte Novo dos Albardeiros, em Reguengos de Monsaraz. Os blocos diagramas, introduzidos na comunidade científica portuguesa por Suzanne Daveau, foram por mim utilizados pela primeira vez, adaptados à arqueologia, na minha própria tese de doutoramento (1989). Aumentam consideravelmente a percepção imediata da implantação dos sítios e são muito úteis para comparar as diversas estratégias de povoamento.

Esta leitura gráfica de uma realidade de terreno, completada pelas anteriores, produz uma visão global e múltipla das diferentes perspectivas em que um sítio arqueológico deve ser encarado e deve ser completada ainda pelo registo geológico e pelas disponibilidades em matérias primas de uso quotidiano e pelas de aquisição a média e longa distância.

\section{A TRANSGRESSÃO FLANDRIANA}

É em 1979 que, tendo-a convidado a colaborar na CLIO, que então dirigia com Joel Serrão, Suzanne responde com o seu artigo «Espaço e Tempo. Evolução do Ambiente geográfico em Portugal ao longo dos tempos pré-históricos» (CLIO 3, 1980, p. 13-37).

A transgressão flandriana era ensinada habitualmente no $1^{\circ}$ ano, na disciplina que então se chamava Pré-História, mas numa perspectiva compreensivelmente genérica.

Quero com isto dizer que se explicava aos alunos que a água proveniente do degelo tinha acrescentado massas líquidas importantes ao Oceano e que, como consequência, a linha de costa se tinha substancialmente alterado. Mas não se usavam exemplos concretos e a inexistência, nos anos 70, de uma disciplina sobre Pré-História peninsular ou de Portugal explicava que não houvesse lugar para que o tema tivesse outro desenvolvimento. 
Por outro lado, se lugares havia em que, à primeira vista, se aplicaria funcionalmente o conceito de transgressão flandriana, seriam o Tejo e o Sado, ao tempo dos mesolíticos. O Sado tinha até então sido pesquisado com o mistério que parece constituir a sua maldição nos últimos 50 anos. O Tejo fora objecto das escavações do Abade Roche, cuja aparente correcção do registo estratigráfico não era enquadrada por qualquer outro tipo de leitura apoiada em bases teóricas que, manifestamente lhe eram desconhecidas. Produziu assim um trabalho asséptico, sem a menor influência sobre a inapta arqueologia portuguesa de então. De onde seria de esperar que Suzanne continuasse a linha das interrogações mesolíticas, aproveitando o buraco negro que Manuel Heleno, Roche e seguidores haviam deixado.

Curiosamente, nada se passa assim e é para dois sítios fundamentais à compreensão da Pré-História das Sociedades Camponesas na Península de Lisboa que Suzanne irá chamar a atenção. Vila Nova de S. Pedro (VNSP) e Zambujal, o primeiro um lugar quase lendário, o segundo conhecido internacionalmente pelos excelentes desenhos das monografias do DAI.

No caso de VNSP, dominara a leitura exclusivamente artefactual e provara-se que, ao contrário do que acontece em Inglaterra, as acções de um amador são ainda de piores consequências que as de um simples violador de monumentos e sítios. E, no caso daquele pobre sítio, se um amador incomoda muita gente, dois amadores...

Suzanne aborda VNSP num ângulo totalmente diferente de Savory, que tentara, como ela o viria a fazer, compreendê-lo de outra forma. Para Savory, a questão era sobretudo a ausência de ordem, a necessidade de se tentar recuperar dos destroços um ângulo de leitura perdido, de se compreender estratigraficamente a sequência de ocupação. Para Suzanne, uma das chaves do crescimento de VNSP (e da sua própria origem) está no Tejo, através do Paúl das Salgadas e da Ribeira de Almoster. E quando visitou VNSP, na minha primeira Campanha de escavações naquelas ruínas de ruínas, com Orlando Ribeiro, foi para aí que olhámos os três, da ponta do esporão, para jusante, para o entalhe würmiano, para o lugar para onde a Ribeira ainda hoje corre.

A subida das águas traduzida na transgressão flandriana explicava uma maior proximidade do Tejo e o Paúl das Salgadas seria o último ponto navegável naquela altura, apenas a escasso tempo de marcha (cerca de 45', como eu próprio descobriria experimentalmente, isto é: a pé) do povoado fortificado.

A mesma leitura para o Zambujal evidenciaria resultados similares.

Temos então uma nova aproximação a sítios clássicos, mas também, como iremos ver, uma insaciável apetência por todo o que de novo se ia fazendo e a actualização da Geografia de Portugal é disso evidência absoluta.

Suzanne Daveau não ficaria por aqui: dois projectos de sorte diversa prolongaram o seu interesse directo ou indirecto pela questão flandriana: Magoito e o Sorraia.

Ao aproximar-se de Magoito (DAVEAU, PEREIRA e ZBYSZEWSKI (1982) - Datation au 14C du site archéologique de la plage de Magoito. CLIO. 4, p. 133-6) era ainda a evolução da linha de costa que a preocupava.

Ao subscrever comigo o projecto ANSOR (GONÇALVES e DAVEAU (1983-84) Programa para o estudo do Baixo-Tejo e afluentes: projecto para o estudo da antropização do Vale do Sorraia. Clio/ARQUEOLOGIA. Lisboa: Uniarq. 1. p. 203-206) 
começaria uma acção que viria a ser obstruída pela estupidez de um lobby ligado à Arqueologia e, fugazmente, a uma autarquia. Ainda assim, do projecto sairia um texto (GONÇALVES e DAVEAU (1985) - A evolução holocénica do Vale do Sorraia e as particularidades da sua antropização (Neolítico e Calcolítico). In Actas da I Reunião do Quaternário Ibérico. Lisboa: Centro de Estudos Geográficos da Universidade de Lisboa. 2. p. 187-197).

A fundamentação do projecto ANSOR tinha a ver com um âmbito geográfico que nada apresentava de inocente. Com efeito, a enorme complexidade do Vale do Sorraia diz naturalmente respeito a dois rios, mas sobretudo a uma das áreas mais dinâmicas no que respeita à origem e evolução das sociedades camponesas. No projecto, sublinhava-se a «escassez pouco usual de bibliografia sobre a área», e depois três estímulos ao povoamento: «a fertilidade dos solos, o relevo propício, a facilidade das deslocações».

O Cabeço do Pé da Erra, onde efectuei duas campanhas de escavação, era uma das motivações para um trabalho conjunto e Suzanne Daveau desceu várias vezes à planície, prospectando mesmo áreas contíguas à antiga povoação de Vila Nova da Erra. Na leitura de Suzanne, «a montante de Coruche, o progressivo deslizar do rio para a direita tem provocado importante captura lateral, que desorganizou o antigo curso paralelo da Ribeira da Erra/Ribeira de Magos. (...) Ficou, portanto, escalonado um conjunto de formas que devem permitir a reconstrução dos episódios que as modelaram. É altamente provável que se encontrem associados nos diversos degraus aluviões solos e artefactos» (GONÇALVES e DAVEAU, 1983-84: 205).

$\mathrm{O}$ assoreamento do vale e a irregularidade da espessura dos depósitos fascinara também Suzanne. A paisagem de Coruche é, conforme as interpretações, um paraíso ou um sonho mau para os geomorfólogos, para os arqueólogos e para os historiadores da paisagem. Para Suzanne, era a abertura de um campo de experimentação de modelos. Mas o obscurantismo pós-salazarista, para usar a expressão de Joaquim Barradas de Carvalho, acabaria por adiar indefinidamente o projecto, recusando-lhe os apoios indispensáveis.

\section{O ESPAÇO E O TEMPO}

A trama de referência indispensável para compreender os homens é, antes de mais, o Tempo. O mesmo se passa naturalmente com a paisagem. Para a paisagem pré-humana, o tempo é muito lento, mas é indispensável para que se entenda a sua evolução. Para os tempos humanos, a influência dos caçadores-recolectores na paisagem seria, em muitos casos, inferior à dos castores, mas após a emergência das sociedades camponesas nada mais será o mesmo e o Tempo acelera de uma forma vertiginosa.

Entendemos assim o Espaço não como uma entidade abstracta, um cadáver numa mesa de autópsia, mas como uma realidade dinâmica, com ritmos derivados da acção humana que não são, durante muito tempo, previsíveis, mesmo num momento histórico aleatoriamente escolhido. 
Durante longos anos, o determinismo geográfico foi uma forma de autoritarismo científico de valor tão reduzido como a Pré-História dos cacos e dos calhaus, descontextualizados por teóricos fascizantes ou pós-modernos. Por outro lado, conhecer exaustivamente um caminho de montanha está longe de corresponder ao conhecimento global do relevo. Qualquer leitura tem forçosamente de ser integrada, sob pena de atomizar o real, através das muitas vias de o fazer, escondendo tantas vezes a mediocridade ou a estupidez dos pretensos observadores.

A um espaço longamente trilhado por geógrafos de terreno, mas de onde o conceito de antropização esteve muitas vezes ausente, Suzanne Daveau acrescentou a dimensão Tempo, ela própria por vezes estranha aos textos arqueológicos pós-modernos. E não deixa de ser interessante sublinhar como lhe foi indiferente o divórcio crescente entre Geografia e História, particularmente visível na Faculdade de Letras de Lisboa após 74, com a supressão do ensino de Pré-História nos diversos cursos de Geografia. O que contrasta com o movimento exactamente inverso feito pela Arqueologia que, neste fim de século, particularmente em Inglaterra e Portugal, recupera da Geografia questões como as da expressão gráfica e arranca com a Arqueologia da Paisagem, uma nova perspectiva com tanto sucesso como bibliografia, no Reino Unido.

Contrariando a corrente, Suzanne (e outros geógrafos, felizmente) compreenderam o erro e o empobrecimento que dele resulta. Geografia e História, Geografia e Arqueologia, como separá-las? 